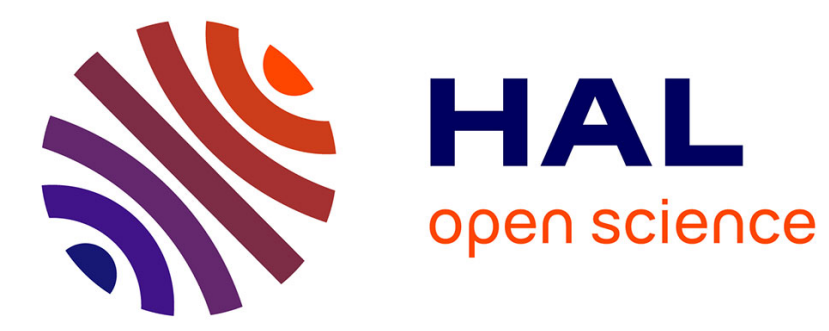

\title{
Laser reactive ablation of thin nitride films
}

E. d'Anna, M. de Giorgi, G. Leggieri, A. Luches, G. Majni, M. Martino, I. Mihailescu, P. Mengucci

\section{To cite this version:}

E. d'Anna, M. de Giorgi, G. Leggieri, A. Luches, G. Majni, et al.. Laser reactive ablation of thin nitride films. Journal de Physique IV Proceedings, 1994, 04 (C4), pp.C4-51-C4-54. 10.1051/jp4:1994409 . jpa-00252547

\section{HAL Id: jpa-00252547 https://hal.science/jpa-00252547}

Submitted on 1 Jan 1994

HAL is a multi-disciplinary open access archive for the deposit and dissemination of scientific research documents, whether they are published or not. The documents may come from teaching and research institutions in France or abroad, or from public or private research centers.
L'archive ouverte pluridisciplinaire HAL, est destinée au dépôt et à la diffusion de documents scientifiques de niveau recherche, publiés ou non, émanant des établissements d'enseignement et de recherche français ou étrangers, des laboratoires publics ou privés. 


\title{
Laser reactive ablation of thin nitride films
}

\author{
E. D'ANNA, M.L. DE GIORGI, G. LEGGIERI, A. LUCHES, G. MAJNI*, M. MARTINO, \\ I.N. MIHAILESCU ${ }^{* *}$ and P. MENGUCCI ${ }^{*}$
}

University of Lecce, Department of Physics, Lecce, Italy

${ }^{*}$ University of Ancona, Department of Materials Science, Ancona, Italy

** Institute of Atomic Physics, Bucharest, Romania

\section{Introduction}

Lasers provide appropriate approaches for the synthesis of materials of interest in modern technology. Laser chemical vapour deposition [1] and synthesis of compounds under direct laser irradiation [2] are among the most successful methods. Also, congruent ablation deposition of compounds (mainly high critical temperature superconductors, but also titanium nitride) was successfully investigated $[3 ; 4]$. A different approach is now emerging [5]: laser reactive ablation (LRA) deposition of thin films. In the LRA deposition method a solid support collects the material ablated by the laser irradiation of the target and reacted with a low-pressure ambient gas.

We deposited titanium and silicon nitride films on silicon wafers at room temperature and at moderate temperature $\left(\left\langle 300^{\circ} \mathrm{C}\right)\right.$ by LRA. Traditional techniques (chemical vapour deposition, reactive evaporation, sputtering) require high-temperature thermal treatments for nitride synthesis, with the consequence of long-range diffusion of dopants and impurities into the substrate. Moreover, this method has the advantage of single-step synthesis and deposition of thin films.

\section{Experimental Apparatus}

Irradiations were performed by using a Lambda Physik LPX $315 i$ Xecl excimer laser $\left(\lambda=308 \mathrm{~nm}, \boldsymbol{\tau}_{\mathrm{FWHM}}=30 \mathrm{~ns}\right)$. Series of 10000 pulses were directed to the $T i$ (or $S i$ ) target surface at a repetition rate of $10 \mathrm{~Hz}$. The fluence was set at $\sim 5 \mathrm{~J} / \mathrm{cm}^{2}$. Before each irradiation series the stainless-steel chamber was evacuated down to $10^{-6} \mathrm{mbar}$. Then, the pressure (p) inside the chamber was fixed, at a given value within the range of $5 \times 10^{-4}-5$ mbar of $\mathrm{N}_{2}$ ( $\mathrm{NH}_{3}$ for Si). The ablated substance was collected on a si wafer, placed on a support either at room temperature or heated at $\mathrm{T}<300^{\circ} \mathrm{C}$. The Si substrate was positioned parallel to the target at a distance $\mathbf{d}=12.5 \mathrm{~mm}$.

After irradiation, both the targets and collecting Si wafers were examined by optical microscopy. Then, the deposited films were investigated by Rutherford backscattering spectrometry (RBS), $x$-ray diffraction (XRD), scanning ( $S E M$ ) and transmission (TEM) electron microscopes and by selected area electron diffraction (SAED).

\section{Experimental Results}

\subsection{Laser ablation of titanium}

The best deposits (gold-yellow spots of elliptical shape with characteristics dimensions larger than $1 \mathrm{~cm}$ ) were observed for a $\mathrm{N}_{2}$ dynamic pressure in the range $1 \times 10^{-3}-3 \times 10^{-2}$ mbar. The deposited films showed a very good adherence already at $100^{\circ} \mathrm{C}$ substrate temperature 
(tests with the Si substrate at room temperature evidenced poor adhesion properties of the deposited film). Typical deposited layer thickness was in the range 200-1000 $\mathrm{nm}$, depending on the $\mathrm{Nz}$ pressure, as determined by numerical simulations of the experimental RBS spectra. SEM inspection did not reveal any undulations, fractures or cracking of the deposited film.

Some characteristics of the LRA deposited films, as evidenced by RBS, TEM, SAED and XRD studies, are as follows:

a) from XRD analysis jt results that the films consist mainly of fcc TiN ( $a=0.424 \mathrm{~nm})$, with small amounts (or none) of $\mathrm{Ti}=\mathrm{N}$; neither metallic Ti nor Ti silicide (TiSiz) were detected;

b) from TEM and SAED analysis it results that film crystallinity varies significantly with the gas pressure. The films deposited at p $>5 \times 10^{-2}$ mbar have a lower content of crystalline phase (partial amorphisation) than the layers deposited at lower pressures

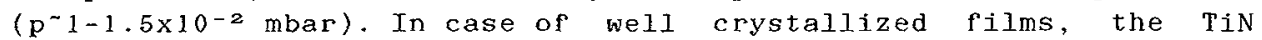
crystallites have characteristic dimensions of $10-15 \mathrm{~nm}$;

c) droplets were observed on some of the films, mainly at relatively high ambient pressure ( $>10^{-2}$ mbar). They have dimensions up to a few $\mu \mathrm{m}$. Their dimensions and their number seem to increase with increasing $\mathrm{N}_{2}$ pressure (Fig. 1). The droplets have the same composition of the deposited film. The absence of metallic Ti can be inferred from the SAED images of the droplets.

\subsection{Laser ablation of silicon}

The best deposits (dark-grey spots of elliptical shape with characteristics dimensions larger than $1 \mathrm{~cm}$ ) were observed for a $\mathrm{NH}_{3}$ dynamic pressure in the range $1 \times 10^{-1}-1$ mbar. Typical film thickness was in the range 200-300 nm, as determined by RBS investigation. The deposited films showed a very good adherence to the Si substrate when the substrate was heated at $\mathrm{T}>100^{\circ} \mathrm{C}$. Ablation in $\mathrm{Nz}$ atmosphere was shown to be ineffective for nitride synthesis, like in preceding experiments on silicon surface nitridation by direct irradiation of silicon wafers in different nitrogen-containing atmospheres [2].

From glazing-angle XRD analysis it results that the deposited films consist mainly of SisN4. Both the low-temperature phase (hexagonal with lattice parameters $a=0.7758 \mathrm{~nm}$ and $c=0.5623 \mathrm{~nm}$ ) and the high-temperature phase (hexagonal with lattice parameters $\mathrm{a}=0.7608 \mathrm{~nm}$ and $\mathrm{c}=0.29109 \mathrm{~nm}$ ) were detected. Peaks from $\mathrm{SiO}_{2}$ (tetragonal with lattice parameters $a=0.4973 \mathrm{~nm}$ and $c=0.695 \mathrm{~nm}$ ) were also detected. By varying the $X$-ray incidence angle from $0.15^{\circ}$ to $0.10^{\circ}$, we noticed that some of the peaks from $\mathrm{Si}_{3} \mathrm{Na}_{4}$ either disappear or are reduced in intensity, while all the peaks from $\mathrm{SiO}_{2}$ are permanent and most of them do not vary in intensity. From this behaviour we can infer that the top layer of the deposited film is richer in dioxide, while the inner layer is richer in nitride.

From SEM inspection we observed that a large amount of droplets are sprayed on all the deposited films (Fig. 2 ).

\section{Discussion}

The deposited titanium nitride films show a good planarity and are adherent to the Si substrate. Deposition of very smooth surfaces is, however, hampered by droplets of various dimensions frequently 
present on the surface. Laser ablation at low $\mathrm{N}_{2}$ pressure greatly reduces droplet number. The presence of nitride droplets suggests the existence of a thin molten layer on the target, covering the interaction area. We suppose that it is from this layer that the droplets are sprayed under the action of the laser pulse and plasma backward recoil pressure. This statement rules out almost completely any contribution to nitridation by reaction during the time of flight of ablated titanium to the substrate and from nitridation on impact on the collecting support by reaction with $\mathrm{N}_{2}$ molecules adhering to the surface. In fact, as regards reaction during the time of flight, a simple calculation [6] shows that it cannot significantly contribute to droplet nitridation. If we assume a droplet velocity of $10 \mathrm{~m} / \mathrm{s}$, which is an upper limit [7], one gets a target-to-substrate transit time of $\sim 1 \mathrm{~ms}$. In the used $\mathrm{N}_{2}$ pressure range, this leads to a 10 Langrnuir exposure. By such an exposure, a metal droplet would be nitridated for 10 atomic layer from the surface, while most of the metal inside the droplet should remain unreacted. 10 atomic layers correspond to a depth of 15-20 A, a small fraction of the droplet dimension (from $0.1 \mu \mathrm{m}$ to a few micrometers in diameter). As already mentioned, SAED studies have shown that the droplets consists of titanium nitride only. Since the largest droplets are in the micrometer range, their nitridation would be insignificantly affected by processes taking place after the impact on the Si support.

As regards reaction between titanium and nitrogen at the collecting support, it is reported by other authors [8] that any amount of $\mathrm{T} i$ in excess of the TiN stoichiometric composition would react with Si, resulting in the formation of titanium silicide (TiSiz).

An analysis of the thermal dynamics of the Ti target under multipulse laser irradiation supports the assumption that the titanium is already nitridated when ablated from the target by the laser pulse. Numerical simulations of the heating of the target indicates that, under our experimental conditions, under multipulse laser irradiation, the duration of the melt is $\sim 150 \mathrm{~ns}$, the depth of the melt is $-1.2 \mathrm{um}$ and the depth of the laser evaporated layer is 0.5 um [6]. This means that a layer undergoes melting process at least twice before ablation. So nitridation process can take place and be enhanced in a liquid phase.

This model should work also in the case of Si targets.

\section{Conclusions}

Good quality films of TiN were obtained by collecting on a Si wafer the substance expelled as an effect of laser ablation of titanium in $\mathrm{N}_{2}$ at $\mathrm{p}^{-10^{-2}}$ mbar. There are no apparent limitations to deposit films of any thickness, by increasing the laser pulse number.

According to our experimental evidence, we suppose that the compound is formed on the irradiated surface. Then it is expelled by laser pulses and it is finally deposited on the Si support.

LRA deposition of silicon nitride films by laser irradiation of Si targets in low pressure ammonia is less efficient and more sensitive to oxygen contamination.

Work supported in part by special project of Italian National Science Council (C.N.R.). 


\section{References}

1. I.W. Boyd, Laser Processing of Thin Films and Microstructures, Springer-Verlag, Berlin, 1987

2. E. D'Anna, G. Leggieri and A. Luches, Thin Solid Films 218 (1992) 219

3. D. Dijkamp, T. Venkatesan, X.D. Wu, S.A. Shaheen, N. Jisrawi, Y.H. Min-Lee, W.L. McLean and M. Croft, Appl. Phys. Lett. 51 (1987) 619

4. J. Narayan, P. Tiwari, X. Chen, J. Singh, R. Chowdhurty and T. Zheleva, Appl. Phys. Lett. 61 (1992) 1290

5. S.R. Nishitani, S. Yoshimura, H. Kawata and M. Yamaguchi, J. Mater. Res. 7 (1992) 725

6. I.N. Mihailescu, N. Chitica, L.C. Nistor, M. Popescu, V.S. Teodorescu, I. Ursu, A. Andrei, A. Luches, M.L. De Giorgi, A. Perrone, B. Dubreuil and J. Hermann, J. Appl. Phys. (in print, 1993)

7. W.M. Steen, Laser Materials Processing, Springer-Verlag, Berlin, 1991

8. A. Armigliato, G. Queirolo and G. Valdre, Phys. Status Solidi A96 (1986) 89

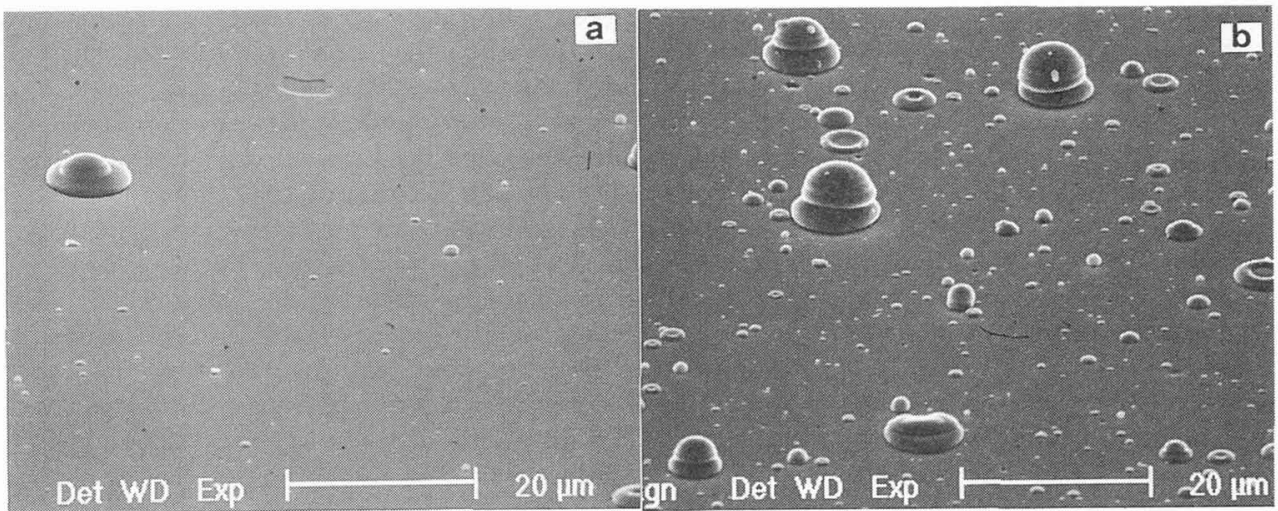

Fig. 1. SEM micrographs of the surface of deposited films after ablation of Ti with $10000 \mathrm{XeCl}$ laser pulses in $\mathrm{N}_{2}$ at a) $\mathrm{p}=0.007 \mathrm{mbar}$ and b) $p=0.5$ mbar.

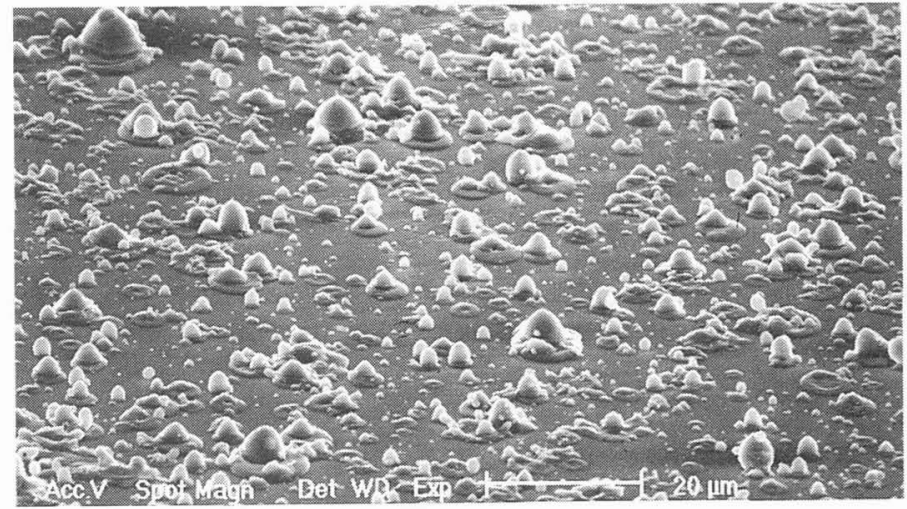

Fig. 2. SEM micrograph of the surface of deposited film after ablation of $\mathrm{Si}$ with $10000 \mathrm{XeCl}$ laser pulses in $\mathrm{NH}_{3}$ at $\mathrm{p}=1 \mathrm{mbar}$. 